\title{
Apposition compound eyes of Spongicoloides koehleri (Crustacea: Spongicolidae) are derived by neoteny
}

\author{
Edward Gaten \\ Department of Biology, University of Leicester, University Road, Leicester, LE1 7RH, UK. E-mail: gat@le.ac.uk
}

\begin{abstract}
Wedding shrimps, Spongicoloides koehleri, spend the adult phase of their life cycle within the cavity of a hexactinellid sponge. Although there is little light at the depths at which the sponges are found, the shrimps do not use the highly sensitive reflecting superposition optics commonly found in other shrimp-like decapods. Instead they have apposition eyes which are virtually free of shielding pigment. It is proposed that this is due to the paedomorphic retention of the larval optics through the process of neoteny.
\end{abstract}

\section{INTRODUCTION}

The family Spongicolidae includes 28 species of marine decapod crustaceans of which members of only one genus, Microprosthema, are free living. The remainder are commensal in hexactinellid sponges with paired adult shrimps (known as wedding shrimps) remaining entrapped within the cavity of the host through most of their life cycle (Saito \& Takeda, 2003). Members of the infraorder Stenopodidea, they are closely related to the caridean shrimps (Richter \& Scholtz, 2001).

Spongicoloides koehleri (Caullery, 1896) was first described from the Bay of Biscay, although specimens have subsequently been taken from the Norfolk Canyon, off Virginia USA. Previous specimens of $S$. koehleri have been recovered at depths between 500 and $1000 \mathrm{~m}$ from Regadrella phoenix Schmidt, 1880 although most related shrimps are found in sponges of the genus Euplectella (Saito \& Takeda, 2003). The taxonomic positions of the various species of Spongicolidea are currently being redefined (Saito \& Takeda, 2003) which will probably result in the species being transferred to the genus Spongiocaris (J. Goy, personal communication).

Most adult decapod shrimps possess compound eyes of the reflecting superposition type (Land, 1976; Gaten, 1998), the only exceptions being Gennadas and related genera in the family Benthesicyminidae (Nilsson, 1990). Within the Stenopodidea, Stenopus hispidus uses this type of optics (Richter, 2002) although the optics used by shrimps within the family Spongicolidae have not been recorded. In this paper the unique eyes of Spongicoloides koehleri are described for the first time and their possible evolutionary origins discussed.

\section{MATERIALS AND METHODS}

Hexactinellid sponges (not identified to species) were collected using the Johnson-Sea-Link submersible at depths of between 510 and $550 \mathrm{~m}$ off the coast of South Carolina, USA $\left(31^{\circ} 44^{\prime} \mathrm{N} 79^{\circ} 05^{\prime} \mathrm{W}\right)$. Adult specimens of Spongiocaris koehleri were removed from the cavity of the sponge and fixed whole, on the ship, in either $10 \%$ formalin or $4 \%$ glutaraldehyde. The specimens were later identified by Dr J. W. Goy of Harding University, Arkansas, USA.

After the specimens were brought to the UK, the eyes were removed, dehydrated and embedded in Spurr resin. They were sectioned at a thickness of $1 \mu \mathrm{m}$, mounted on glass slides and stained in $1 \%$ toluidine blue in $1 \%$ borax solution.

\section{RESULTS}

The adult specimens of Spongiocaris koehleri were almost transparent at the time of capture. A pair of stalked compound eyes (approximately $1 \mathrm{~mm}$ in diameter in an adult specimen) was present beneath the rostrum (Figure 1A). The eyes contained very little shielding pigment, although they appeared pink when the animal was alive (P.J. Herring, personal communication). This was probably due to the presence of the visual pigment rhodopsin within the rhabdoms. When seen from the lateral aspect, the eye appeared to possess a ring of dark pigment (Figure 1B) which, when the eye was viewed dorsally, could be seen to extend diagonally across the eye (Figure 1C). There was also an incomplete proximal ring of dark pigment around the junction between the eye and the eyestalk. The facets appeared to be circular and around 80 to $85 \mu \mathrm{m}$ in diameter. They were not arranged in any clearly defined pattern (Figure 1B).

Longitudinal sections through the eye show a cone cell layer and a retinula cell layer, each constituting about half of the length of the ommatidia (Figure 2A). The eye has a wide field of view (around $230^{\circ}$ in the antero-posterior plane) and a broad inter-ommatidial angle (about $5^{\circ}$, measured from the sectioned eye). Distally there is a thin, parallel-sided cornea with two corneagenous cells immediately underneath (Figure 2B). The crystalline cones are formed by four cone cells with rounded nuclei that fill much of the distal part of the cells. In transverse section, the cones appear rounded over most of their length but they are not of a regular shape (Figure 2C). The cones narrow proximally to form a cone stalk with 

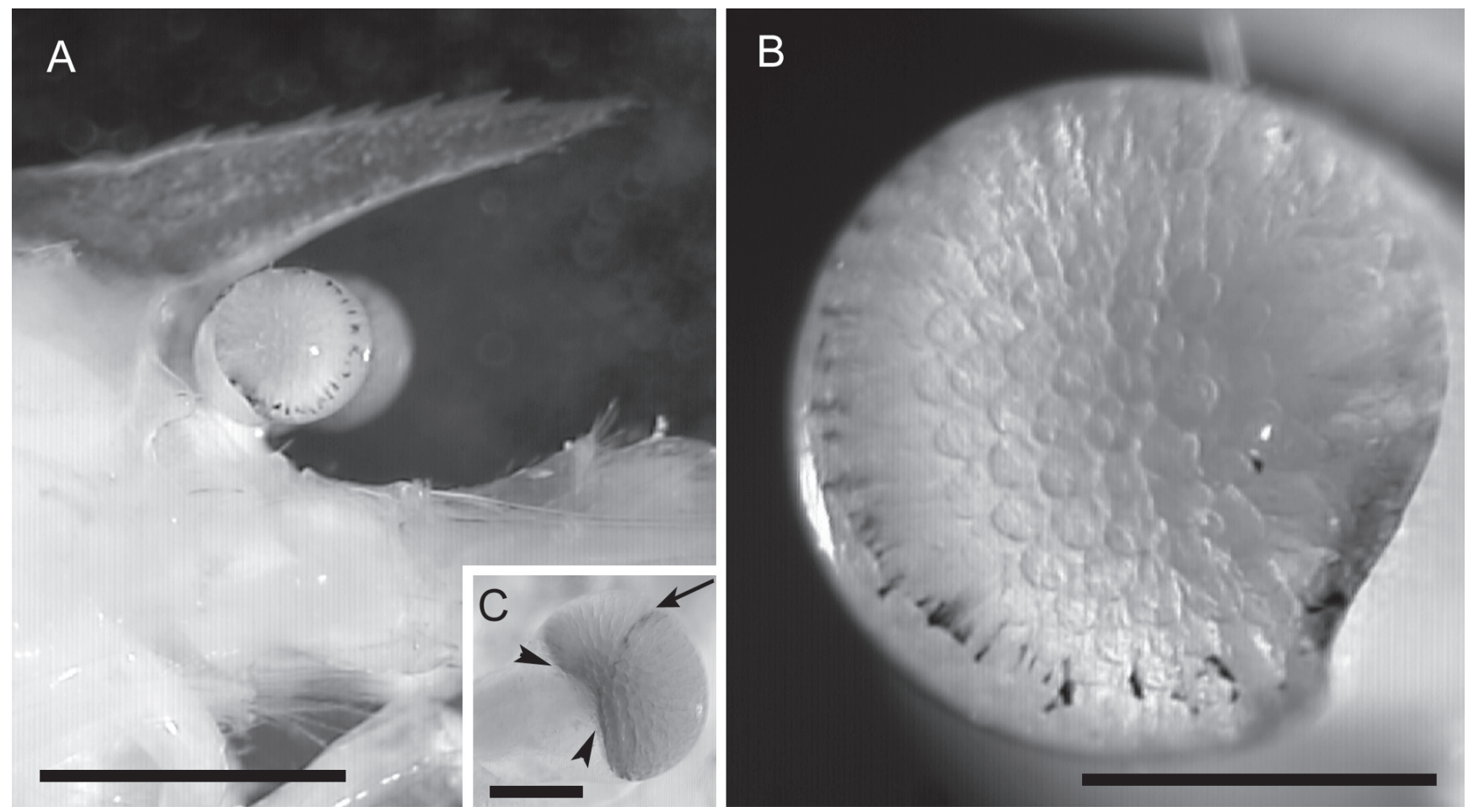

Figure 1. (A) The compound eyes of live Spongicoloides koehleri are unpigmented apart from a ring of shielding pigment visible from the lateral aspect; (B) lateral view of the left eye showing circular facets and ring of shielding pigment; $(\mathrm{C})$ dorsal view of the right eye showing diagonal line of shielding pigment (arrow); some pigment is present around the eye margin (arrowheads). Scale bars: A, 2 mm; B, C, 0.5 mm.

no noticeable change in density. The proximal ends of the cones project through the layer of retinula cell nuclei and abut the distal ends of the rhabdoms (Figure 2B).

The distal part of the rhabdom has three lobes (Figure 2D) whereas the proximal rhabdoms are more rounded in cross section (Figure 2E). The rhabdoms are short (up to 85 $\mu \mathrm{m}$ in length), extending no more than half of the depth of the retinula cell layer (Figure 2B), and they are indistinctly banded.

Occasional nuclei can be seen below the rhabdoms which may belong to tapetal cells although no eyeshine was seen in the live specimens. Retinula cell axons extend through the basement membrane and project to the lamina ganglionaris.

No shielding pigment was found in any of the retinula cells or in between the cones in distal pigment cells (except for the thin ring of pigment mentioned earlier).

\section{DISGUSSION}

The reflecting superposition eyes of shrimp-like decapods from shallow water are constructed according to a consistent pattern (e.g. Palaeomonetes pugio—Doughtie \& Rao, 1984). The basic constituents include crystalline cones that are square in cross section; distal pigment cells containing mobile shielding and reflecting pigments; retinula cells containing mobile proximal shielding pigment; fusiform rhabdoms built up of alternating layers of microvilli; and a tapetum below the rhabdom layer.

With increasing depth, many of these characteristics are modified in various crustacean species as they adapt to the decrease in available light. These include loss of mobility of the pigments and an overall reduction in the quantity of shielding pigment in the eye (Gaten et al., 1990). Changes are also apparent in the structure of the rhabdoms of mesopelagic shrimps (Gaten et al., 2003) as they seek to maximize absolute sensitivity or contrast enhancement (Gaten et al., 2004).

However, the eye of Spongiocaris koehleri shows departures from the characteristics seen in the eyes of shallow water decapods that do not seem to be related to the increased depth at which the animals were found. The major differences seen are the presence of circular facets and the lack of shielding pigment within the eye.

Square-faceted reflecting superposition eyes are found in most decapods, with the exception of various crabs, hermit crabs and shrimps of the family Benthesicyminidae (formerly Aristeidae-Gaten, 1998). Circular facets are found in apposition, refracting superposition and parabolic superposition eyes (Nilsson, 1989). The characteristics of superposition eyes include the presence of a clear zone between the crystalline cones and the rhabdoms and a means of redirecting the light within the dioptric layer to the target rhabdom. The virtual absence of any shielding pigment within the eyes of S. koehleri means that the concept of a clear zone did not apply to these eyes. The crystalline cones did not show any of the adaptations seen in superposition eyes, such as square mirror boxes (reflecting superposition), parabolic curvature of the cone walls (parabolic superposition) or any sign of a refractive index gradient (usually detectable by variable staining in the crystalline cones of refracting superposition eyes). No eyeshine, another common indicator of superposition optics, was reported from the live animals. Although larval decapod eyes show preadaptations 


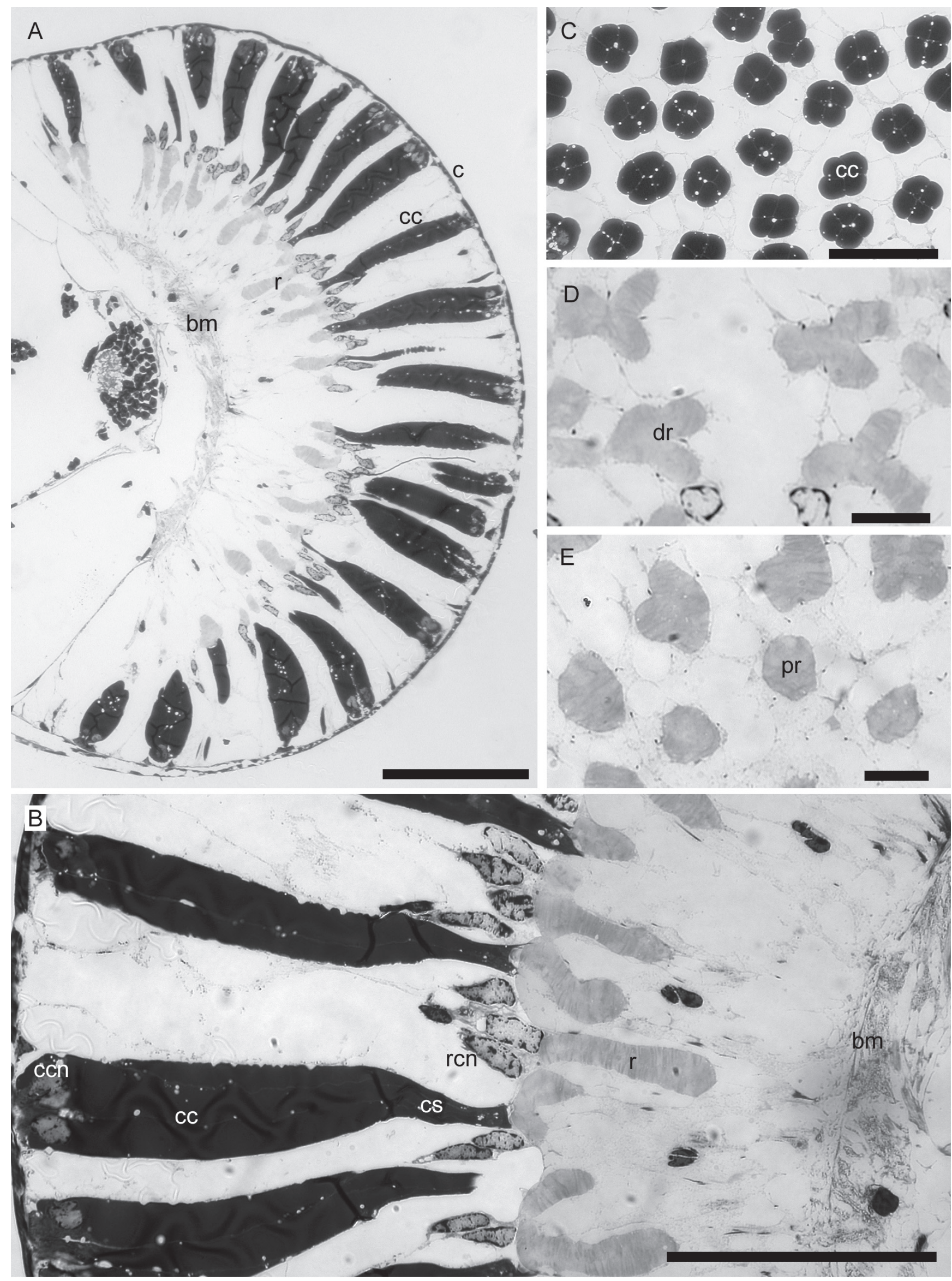

Figure 2. (A) Section through the middle of the eye in the antero-posterior plane; (B) a group of ommatidia, showing crystalline cones (cc), cone cell nuclei (ccn), cone stalk (cs), retinula cell nuclei ( $\mathrm{rcn}$ ), rhabdom (r) and basement membrane (bm); (C) cross section showing quadripartite crystalline cones; (D) cross section of the three-lobed distal rhabdoms (dr); (E) proximally, the rhabdoms assume a cylindrical form (pr). Scale bars: A, $200 \mu \mathrm{m} ; \mathrm{B}, \mathrm{C}, 100 \mu \mathrm{m} ; \mathrm{D}, \mathrm{E}, 25 \mu \mathrm{m}$. 
for superposition image formation in the absence of distal shielding pigment (Nilsson, 1983), proximal pigment would be required in this eye to avoid the problem of light stimulating adjacent, non-target rhabdoms.

Shielding pigment was not seen in the eyes of $S$. koehleri except for a small amount around the margin of the eye and in a circle facing laterally. Shielding pigments normally serve to reduce the amount of light reaching the rhabdoms, but no function can be ascribed to the small amount of pigment seen in this case.

The combination of virtually unpigmented eyes and circular facets is only commonly found in larval crustaceans which all use apposition optics initially and which rely on transparency for camouflage in the planktonic environment (Nilsson, 1983). The combination of a wide field of view and low resolution (large inter-ommatidial angle) are also typical of larval eyes. The major difference between larval eyes and the adult eyes of $S$. koehleri is the absence of proximal shielding pigment, resulting in a further loss of resolution.

Most deep-water spongicolids, including S. koehleri, produce small numbers of large eggs with juveniles hatching directly from the eggs (Saito \& Takeda, 2003). Such lecithotrophic development is seen in other mesopelagic decapods (see Gaten \& Herring, 1995) although in these cases, the newlyhatched juveniles bear eyes that already show evidence of the development of reflecting superposition optics.

The presence of reflecting superposition eyes in most other shrimp-like decapods (Gaten, 1998) and within other members of the infraorder Stenopodidea (Richter, 2002) indicates that this type of optics is plesiomorphic for this group. Given that paedomorphosis has often been implicated in crustacean evolution (e.g. Gould, 1977; Richter, 2002), I would suggest that the unique eyes of spongicolid shrimps have arisen through this process. It has been suggested that neoteny is a possible explanation for the presence of apposition optics in brachyuran eyes (Land, 1980), although in their case a heavily pigmented and relatively high resolution eye results. In the eyes of S. koehleri, the apposition optics that are retained in the adult are of low resolution, implying that life within the cavity of a sponge requires sensitivity to light, but not the resolution of any fine detail, requirements fulfilled by the neotenous retention of the larval eye.

It is not clear how the retention of apposition optics would benefit this species. Apposition eyes are apparently sufficient for locating the sponge initially as a juvenile and later when approaching sexual maturity (Saito et al., 2001). Further specialization of the eyes would presumably be of no real advantage in the light-deprived environment of the adults. Gould (1977) has suggested that neoteny in animals showing extended parental care of the young ( $\mathrm{K}$ selected) results in retarded differentiation of juvenile features. In the case of S. koehleri the avoidance of overspecialization of the eye (in the form of superposition optics) would result in a smaller eye with fewer facets compared to most other shrimp-like decapods, possibly leading to a reduction in metabolic cost to the animal.
I would like to thank Professor Peter Herring (National Oceanography Centre, UK) who caught the shrimps and brought them to my attention; Dr Joe Goy (Harding College, Arkansas, USA) who kindly identified the specimens; and Dr Stefan Richter (Friedrich-Schiller-Universität Jena, Germany) for his expert insight into the process of paedomorphosis.

\section{REFERENCES}

Doughtie, D.G. \& Rao, K.R., 1984. Ultrastructure of the eyes of the grass shrimp, Palaemontes pugio. General morphology, and light and dark adaptation at noon. Cell and Tissue Research, 238 , 271-288.

Gaten, E., 1998. Eye structure and phylogeny: is there an insight? The evolution of superposition eyes in the Decapoda (Crustacea). Contributions to Zoology, 67, 223-235.

Gaten, E. \& Herring, P.J., 1995. Morphology of the reflecting superposition eyes of larval oplophorid shrimps. Fournal of Morphology, 225, 19-29.

Gaten, E., Shelton, P.M.J., Chapman, C.J. \& Shanks, A.M., 1990. Depth related variation in the structure and functioning of the compound eye of the Norway lobster Nephrops norvegicus. Fournal of the Marine Biological Association of the United Kingdom, 70, 343-355.

Gaten, E., Shelton, P.M.J. \& Nowel, M.S., 2003. Variations in the rhabdom structure of oplophorid shrimps. Fournal of Morphology, 257, 87-95.

Gaten, E., Shelton, P.M.J. \& Nowel, M.S., 2004. Contrast enhancement through structural variations in the rhabdoms of oplophorid shrimps. Marine Biology, 145, 499-504.

Gould, S.J., 1977. Ontogeny and phylogeny. Cambridge, Massachusetts: Belknap Press.

Land, M.F., 1976. Superposition images are formed by reflection in the eyes of some oceanic decapod crustacea. Nature, London, 263, 764-765.

Land, M.F., 1980. Compound eyes: old and new optical mechanisms. Nature, London, 287, 681-686.

Nilsson, D.E., 1983. Evolutionary links between apposition and superposition optics in crustacean eyes. Nature, London, 302, 818-821.

Nilsson, D.E., 1989. Vision optics and evolution. BioScience, 39, 298-307.

Nilsson, D.E., 1990. Three unexpected cases of refracting superposition eyes in crustaceans. Fournal of Comparative Physiology, 167A, 71-78.

Richter, S., 2002. Evolution of optical design in the Malacostraca (Crustacea). In The crustacean nervous system (ed. K. Wiese), pp. 512-524. Heidelberg: Springer.

Richter, S. \& Scholtz, G., 2001. Phylogenetic analysis of the Malacostraca (Crustacea). Journal of Zoological Systematics and Evolutionary Research, 39, 113-136.

Saito, T. \& Takeda, M., 2003. Phylogeny of the family Spongicolidae (Crustacea: Stenopodidea): evolutionary trend from shallowwater free-living to deep-water sponge-associated habitat. Fournal of the Marine Biological Association of the United Kingdom, 83, 119-131.

Saito, T., Uchida, I. \& Takeda, M., 2001. Pair formation in Spongicola japonica (Crustacea: Stenopodidea: Spongicolidae), a shrimp associated with deep-sea hexactinellid sponges. Fournal of the Marine Biological Association of the United Kingdom, 81, 789-797.

Submitted 29 September 2006. Accepted 7 December 2006. 